\title{
Statin Use After Diagnosis of Colon Cancer and Patient Survival
}

\author{
Philip W. Voorneveld, ${ }^{1, *}$ Marlies S. Reimers, ${ }^{2, *}$ Esther Bastiaannet, ${ }^{2,3}$ Rutger J. Jacobs, ${ }^{1}$ \\ Ronald van Eijk, ${ }^{4}$ Marjolein M. J. Zanders, ${ }^{5}$ Ron M. C. Herings, ${ }^{6}$ Myrthe P. P. van Herk-Sukel, ${ }^{6}$ \\ Liudmila L. Kodach, ${ }^{1}$ Tom van Wezel, ${ }^{4}$ Peter J. K. Kuppen, ${ }^{2}$ Hans Morreau, ${ }^{4}$ \\ Cornelis J. H. van de Velde, ${ }^{2}$ James C. H. Hardwick, ${ }^{1,}$ and Gerrit Jan Liefers ${ }^{2, \S}$
}

\begin{abstract}
${ }^{1}$ Department of Gastroenterology \& Hepatology, Leiden University Medical Center, the Netherlands; ${ }^{2}$ Department of Surgery, Leiden University Medical Center, the Netherlands; ${ }^{3}$ Department of Gerontology \& Geriatrics, Leiden University Medical Center, the Netherlands; ${ }^{4}$ Department of Pathology, Leiden University Medical Center, the Netherlands; ${ }^{5}$ Comprehensive Cancer Centre, the Netherlands; and ${ }^{6}$ PHARMO Institute for Drug Outcomes Research, the Netherlands
\end{abstract}

BACKGROUND \& AIMS: Statin use has been associated with a reduced incidence of colorectal cancer and might also affect survival of patients diagnosed with colon cancer. Statins are believed to inhibit Ras signaling and may also activate the bone morphogenetic protein (BMP) signaling pathway in colorectal cancer cells. We investigated the effects of statins on overall survival of patients with a diagnosis of colon cancer, and whether their effects were associated with changes in KRAS or the BMP signaling pathways. METHODS: Data were derived from the PHARMO database network (Netherlands) and linked to patients diagnosed with colon cancer from 2002 through 2007, listed in the Eindhoven Cancer Registry. We obtained information on causes of death from statistics Netherlands. We constructed a tissue microarray of 999 colon cancer specimens from patients who underwent surgical resection from 2002 through 2008. Survival was analyzed with statin user status after diagnosis as a time-dependent covariate. Multivariable Poisson regression survival models and Cox analyses were used to study the effect of statins on survival. Tumor tissues were analyzed by immunohistochemistry for levels of SMAD4, BMPR1A, BMPR1B, and BMPR2 proteins. Tumor tissues were considered to have intact BMP signaling if they contained SMAD4 plus BMPR1A, BMPR1B, or BMPR2. DNA was isolated from tumor tissues and analyzed by quantitative polymerase chain reaction to detect mutations in KRAS. The primary outcome measures were overall mortality and cancer-specific mortality. RESULTS: In this cohort, $21.0 \%$ of the patients (210/999) were defined as statin users after diagnosis of colon cancer. Statin use after diagnosis was significantly associated with reduced risk of death from any cause (adjusted relative risk [RR], 0.67; 95\% confidence interval [CI], 0.51-0.87; $P=.003$ ) and death from cancer (adjusted RR, 0.66; 95\% CI, $0.49-0.89 ; P=.007)$. Statin use after diagnosis was associated with reduced risk of death from any cause or from cancer for patients whose tumors had intact BMP signaling (adjusted RR, 0.39 ; 95\% CI, 0.22-0.68; $P=.001$ ), but not for patients whose tumors did not have BMP signaling (adjusted RR, 0.81; 95\% CI, $0.55-1.21 ; P=.106 ; P<.0001$ for the interaction). Statin use after diagnosis was not associated with reduced risk of death from any cause or from cancer for patients whose tumors did not contain KRAS mutations (adjusted RR, 0.81; 95\% CI, $0.56-1.18 ; P=.273$ ) or whose tumors did have KRAS mutations (adjusted RR, 0.59; 95\% CI 0.35-1.03; $P=.062 ; P=.90$ for the interaction). CONCLUSIONS: In an analysis of 999 patients with a diagnosis of colon cancer, we associated statin with reduced risk of death from any cause or from cancer. The benefit of statin use is greater for patients whose tumors have intact BMP signaling, independent of KRAS mutation status. Randomized controlled trials are required to confirm these results.

Keywords: Colorectal cancer; Signal Transduction; Patient Selection; Cholesterol-lowering Drug.

lthough colorectal cancer survival has doubled in A the last 40 years, 5-year survival remains low at only $65 \%{ }^{1}$ Current chemotherapy treatment for colorectal cancer results in significant toxicity, limiting its use in early stage disease, in the elderly, and in patients with comorbidity, so that there is a clear unmet clinical need for new, less toxic treatment options. Previously, aspirin has been shown to increase survival when used after diagnosis, thus providing a potential new minimally toxic adjuvant treatment option for colorectal cancer. ${ }^{2,3}$ Statins may represent such a treatment option as well, either alone or in combination with aspirin. Aside from their proven efficacy in primary and secondary prevention of cardiovascular morbidity and mortality, ${ }^{4}$ statins have been shown, in several but not all studies, to reduce the risk of developing colorectal cancer. ${ }^{5}$ In vitro and in vivo studies indicate that statins inhibit proliferation and induce apoptosis in colorectal cancer cells. ${ }^{6,7}$ However, the exact molecular mechanism by which statins influence colorectal cancer remains under debate. Cancer therapy is increasingly focused on personalized therapy via pharmacologic modulation of specific molecular pathways targeted to sensitive tumors identified by molecular subtyping; statins could potentially be more effective in a specific subgroup of cancers.

There are several potential molecular mechanisms of action to explain the therapeutic effects of statins in

*Authors share co-first authorship; ${ }^{\S}$ Authors share co-senior authorship.

Abbreviations used in this paper: BMP, bone morphogenetic protein; $\mathrm{Cl}$, confidence interval; $\mathrm{RR}$, rate ratio.

(Q) Most current article

(C) 2017 by the AGA Institute 0016-5085/\$36.00

http://dx.doi.org/10.1053/j.gastro.2017.05.011 


\section{EDITOR'S NOTES \\ BACKGROUND AND CONTEXT}

The long-term use of statins has been linked to improved survival after a diagnosis of colorectal cancer but the mechanism for this protective effect is unclear.

\section{NEW FINDINGS}

The researchers show that statin use after a diagnosis of colorectal cancer is associated with improved cancer specific survival. This effect was strongest in cancers with an intact BMP cell signaling pathway and independent of cancer KRAS mutations.

\section{LIMITATIONS}

This is a retrospective molecular pathological epidemiological study.

\section{IMPACT}

BMP pathway analysis of colorectal cancers could help identify patients that benefit most from statin use.

colorectal cancer. Statins inhibit 3-hydroxy-3-methylglutaryl coenzyme A (HMG-CoA) reductase; an enzyme that plays an essential role in mevalonate synthesis. Inhibition of the mevalonate pathway not only disrupts cholesterol synthesis, but also farnesyl pyrophosphate synthesis, which is essential for the prenylation of GTPases like $K R A S^{8}$ It is therefore thought that statins might act on colorectal cancer by inhibiting KRAS. KRAS mutations are prevalent in $40 \%$ of colorectal cancers and result in constitutively active form of KRAS.

Another theory hypothesizes that statins act through activation of the bone morphogenetic protein signaling (BMP) pathway. Statins activate the BMP pathway in bone, ${ }^{10}$ and we have previously shown that they also do this in colorectal cancer. ${ }^{11}$ Interestingly, statins are only effective in colorectal cancer cells where BMP signaling is intact. ${ }^{7}$ BMP signaling is frequently disrupted in colorectal cancer through loss of SMAD4, the central component of the signaling cascade, or reduced BMP receptor expression. ${ }^{12,13}$

The aim of our study was to evaluate whether statins might be effective as adjuvant therapy in colon cancer by correlating post-diagnosis statin use with patient survival in a cohort in which we have previously observed a survival benefit with aspirin use after diagnosis. Secondly, we tried to uncover the molecular background in which statins are able to execute their tumor-suppressive function, thereby considering the KRAS mutational status and the BMP signaling pathway functionality in relation to statin use and patient survival.

\section{Materials and Methods}

\section{Retrospective Study Cohort}

All patients diagnosed with colon cancer between 2002 and 2007 were selected from the Eindhoven Cancer Registry. This southern region of the Netherlands is served by 10 hospitals each serving a population between 150,000 and 250,000 people. Data on statin use (simvastatin, pravastatin, cerivastatin, fluvastatin, atorvastatin, and rosuvastatin) was derived from the PHARMO database network (PHARMO, Netherlands). The central patient database of the PHARMO record linkage system has recently been linked to the Eindhoven Cancer Registry database; this is described in detail by Van Herk-Sukel et al. ${ }^{14}$ Information about cause of death was obtained from Statistics Netherlands. Formalin-fixed paraffin-embedded tissue blocks were retrieved from 1026 patients with colon cancer who had a surgical resection between 2002 and $2008 .^{15}$ Rectal cancers were not included because many of these tissue specimens will have been exposed to preoperative radiotherapy, which may influence tumor molecular characteristics. Twenty-seven patients with more than 1 colon tumor at the time of diagnosis were excluded for this study; thus the total cohort consisted of 999 patients.

\section{TMA Production}

Three 1.0-mm diameter cores were obtained from formalinfixed paraffin-embedded tumor blocks and transferred into a receiver paraffin block using the TMA Master (3D Histech, Budapest, Hungary) as previously described. ${ }^{15}$ Representative tumor sites were identified by 2 independent researchers using H\&E-stained sections (with a qualified pathologist confirming the identification of the tumor).

\section{Immunohistochemistry and TMA Scoring System}

Determination of microsatellite stability status by immunohistochemical analysis has been previously described. ${ }^{15}$ SMAD4 and BMP receptors were stained according to previously described methods. ${ }^{16}$ Examples of tumor core stainings are shown in Supplementary Figure 1. Scoring was performed in a blinded fashion by 2 investigators (P.V. and J.H.) independently according to previously described methods. ${ }^{16}$ Three cores per tumor were analyzed and an average score per tumor was calculated. The concordance between investigators was 87\% ( $\kappa=0.70,95 \%$ confidence interval [CI] 0.604-0.796). Final scoring was reached by consensus. The tumors were divided in "intact BMP signaling" and "non-intact BMP signaling" based on the expression of SMAD4, BMPR1a, BMPR1b, and BMPR2. The tumor was designated as having "non-intact BMP signaling" if either SMAD4 or one of the BMP receptors scored negative.

\section{KRAS Mutation Analysis}

DNA was extracted from 2.0-mm diameter cores taken randomly from 663 of the 999 blocks, as previously described. $^{15}$ For determination of KRAS mutations status, hydrolysis probe assays were performed for the major known mutations (hotspots) in codon 12 and 13 for KRAS; c.34G $>\mathrm{A}$; p.G12S, c.34G $>$ C; p.G12R, c.34G $>$ T; p.G12C, c.35G $>$ A; p.G12D, c.35G $>$ C; p.G12A, c.35G $>$ T; p.G12V, c.38G $>$ A; p.G13D and c.37G $>$ T; p.G13C, as previously described. ${ }^{15}$ Hydrolysis probe assays were analyzed using quantitative polymerase chain reaction analysis software (CFX manager version 3/0, Bio-Rad, Hercules, CA). Mutation detection was performed blindly by 2 independent observers (M.S.R. and R.E.).

\section{Statistics}

Definition of statin user. Statistical analyses were performed using the statistical packages SPSS (version 20.0 for 
Windows, IBM SPSS statistics, Armonk, NY) and STATA/SE (version 12 for windows, StataCorp LLC, College Station, TX). A $P$ value of $<.05$ was considered statistically significant. The vital status of patients (alive/dead) was identified via medical records or through linking the Eindhoven Cancer registry data with the municipal population registries that have information on the vital status (alive or deceased). Followup started 30 days from diagnosis of colon cancer (T0), and was ended January 2012 or at the date of death. Patients who died within 30 days after diagnosis were excluded from the survival analyses (2.4\%). Statin non-users were classified as those who never had a prescription for statin or had a prescription for less than 14 consecutive days after diagnosis of colon cancer. Statin users were defined as those who had been given a prescription for statins for 14 days or more after a colon cancer diagnosis.

Time-dependent survival analyses. A timedependent exposure survival analysis for Overall Mortality (deaths from any cause) and Cancer-Specific Mortality (deaths from cancer) was performed in which patients were defined as non-users from T0 to the first use and users from first use to the end of the follow-up. A parametric survival model with an exponential (Poisson) distribution was used. Secondly, a Cox proportional hazard model was used with statin use as a timevarying covariate to confirm the analyses. Adjustments for potential confounders were made for sex, age (continuous), stage (pathologic stage or clinical stage when pathologic stage was unknown), adjuvant chemotherapy (yes/no), grade, year of incidence, microsatellite status, and comorbidity (yes/no). Comorbidities included respiratory disease, cardiovascular disease, digestive disease, musculoskeletal disease, neurologic disease, or endocrine disease. Subgroup analyses were performed for sex, age, stage, grade, chemotherapy, aspirin use after diagnosis, and frequent use of statin $(\geq 3, \geq 5$, or $\geq 7$ prescriptions). Frequent users were defined as patients who had a given number (or more) consecutive repeat prescriptions for statins. User time started after the completion of the 3,5 , or 7 prescriptions. Survival time of patients who had $<3,5$, or 7 refills and time before the prescription requirements of the frequent users was classified as non-user time in this analysis.

Sensitivity analyses for ACE inhibitors and benzodiazepines. A sensitivity analyses was performed to assess the association of 2 other groups of medicine, benzodiazepines and ACE inhibitors, and survival. For this, the same methodology as for statin use was followed and a timedependent parametric survival model with an exponential (Poisson) distribution was used, in which patients were defined as non-users from $\mathrm{T} 0$ to the first use and users from first use to the end of the follow-up. Adjustments for potential confounders were made for sex, age (continuous), stage (pathologic stage or clinical stage when pathologic stage was unknown), adjuvant chemotherapy (yes/no), grade, year of incidence, microsatellite status, and comorbidity (yes/no). An extra analysis was performed excluding statin users from the group of post-diagnosis ACE inhibitors users.

A lag of 6 months. In another analysis, a lag of 6 months after diagnosis was introduced to reduce any bias in prescribing that may arise because of impending death, although our definition of a statin user was specifically chosen to minimize this sort of bias caused by disease progression.
Molecular subtypes. Finally, differential associations of statin use with cancer-specific mortality by tumor molecular subtype were investigated by subgroup analyses for intact BMP signaling status and KRAS mutation status followed by an interaction analysis.

\section{Results}

\section{Statin use After Colon Cancer Diagnosis and Survival}

In total, 999 colon cancer patients were included in this study. Table 1 shows the characteristics of the population according to statin use or non-use after diagnosis and Figure 1 shows a flow diagram of the patient inclusion in the various analyses. In this cohort, 21.0\% (210/999) were defined as statin users after diagnosis. During follow-up until January 2012, 465 deaths were recorded, of whom 69 were statin users (32.9\% of statin users) and 396 were nonusers (50.2\% of nonusers). Statin users were predominately male, older age, and had more comorbidities. Furthermore, tumors found in statin users have a lower stage than tumors found in non-users $(P=.005)$. The mean and median duration of prescriptions was 76.6 and 90 days, respectively, and the mean number of prescriptions per patient was 23 (range, 1-215). Overall, 51.7\% of the

Table 1.Baseline Characteristics of the Colon Cancer Patients According to Use of Statin After Diagnosis

\begin{tabular}{|c|c|c|c|c|}
\hline & $\begin{array}{l}\text { All patients } \\
\qquad(\mathrm{N}=999)\end{array}$ & $\begin{array}{c}\text { Statin } \\
\text { non-users } \\
(\mathrm{N}=789)\end{array}$ & $\begin{array}{c}\text { Statin } \\
\text { users } \\
(\mathrm{N}=210)\end{array}$ & $\begin{array}{c}P \\
\text { value }\end{array}$ \\
\hline \multicolumn{5}{|l|}{ Sex } \\
\hline Male & $505(50.6)$ & $379(48.0)$ & $126(60.0)$ & \multirow[t]{2}{*}{.002} \\
\hline Female & $494(49.4)$ & $410(52.0)$ & $84(40.0)$ & \\
\hline \multicolumn{5}{|l|}{ Age } \\
\hline$<65$ & 342 (34.2) & $282(35.7)$ & 60 (28.6) & \multirow[t]{3}{*}{$<.001$} \\
\hline $66-74$ & $304(30.4)$ & $211(26.7)$ & $93(44.3)$ & \\
\hline$\geq 75$ & $353(35.4)$ & $296(37.5)$ & $57(27.1)$ & \\
\hline \multicolumn{5}{|c|}{ Year of diagnosis } \\
\hline 2002-2004 & 451 (45.2) & 354 (44.9) & 97 (46.2) & \multirow[t]{2}{*}{.732} \\
\hline 2005-2007 & $548(54.8)$ & $435(55.1)$ & $113(53.8)$ & \\
\hline \multicolumn{5}{|l|}{ Disease stage } \\
\hline I & 138 (13.8) & 99 (12.6) & 39 (18.6) & \multirow[t]{5}{*}{.005} \\
\hline ॥ & $402(40.2)$ & $308(39.0)$ & $94(44.8)$ & \\
\hline III & $287(28.7)$ & $231(29.3)$ & $56(26.7)$ & \\
\hline IV & 169 (16.9) & 149 (18.9) & $20(9.5)$ & \\
\hline Unknown & $3(0.3)$ & $2(0.3)$ & $1(0.5)$ & \\
\hline \multicolumn{5}{|l|}{ Comorbidity } \\
\hline No & $443(44.3)$ & $401(50.8)$ & $42(20.0)$ & \multirow[t]{2}{*}{$<.001$} \\
\hline Yes & $556(55.7)$ & 388 (49.2) & $168(80.0)$ & \\
\hline \multicolumn{5}{|c|}{ Microsatellite status } \\
\hline $\mathrm{MSI}$ & $90(9.0)$ & $70(8.9)$ & $20(9.5)$ & \multirow[t]{3}{*}{.727} \\
\hline MSS & $870(87.1)$ & $690(87.5)$ & $180(85.7)$ & \\
\hline Unknown & $39(3.9)$ & $29(3.7)$ & $10(4.8)$ & \\
\hline \multicolumn{5}{|l|}{ Chemotherapy } \\
\hline No & $691(69.2)$ & $542(68.7)$ & $149(71.0)$ & \multirow[t]{2}{*}{.529} \\
\hline Yes & $308(30.8)$ & 247 (31.3) & $61(29.0)$ & \\
\hline
\end{tabular}

MSI, microsatellite instable tumors; MSS, microsatellite stable tumors. 


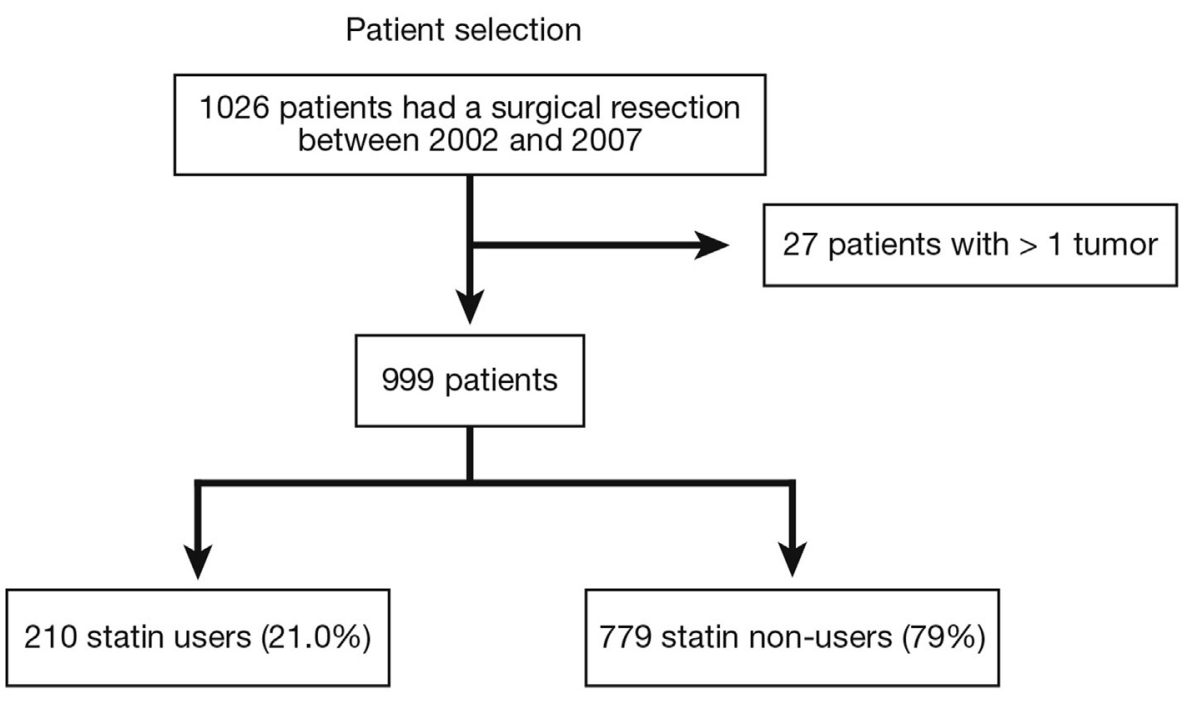

KRAS mutation analysis

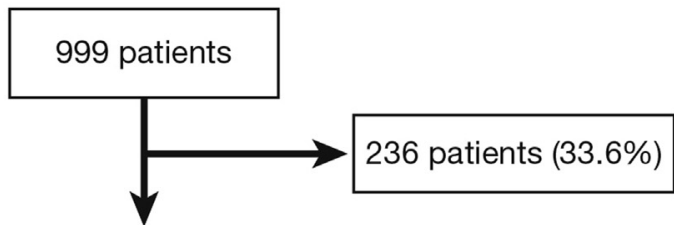

DNA extraction (randomly chosen): 663 patients $(66.4 \%)$

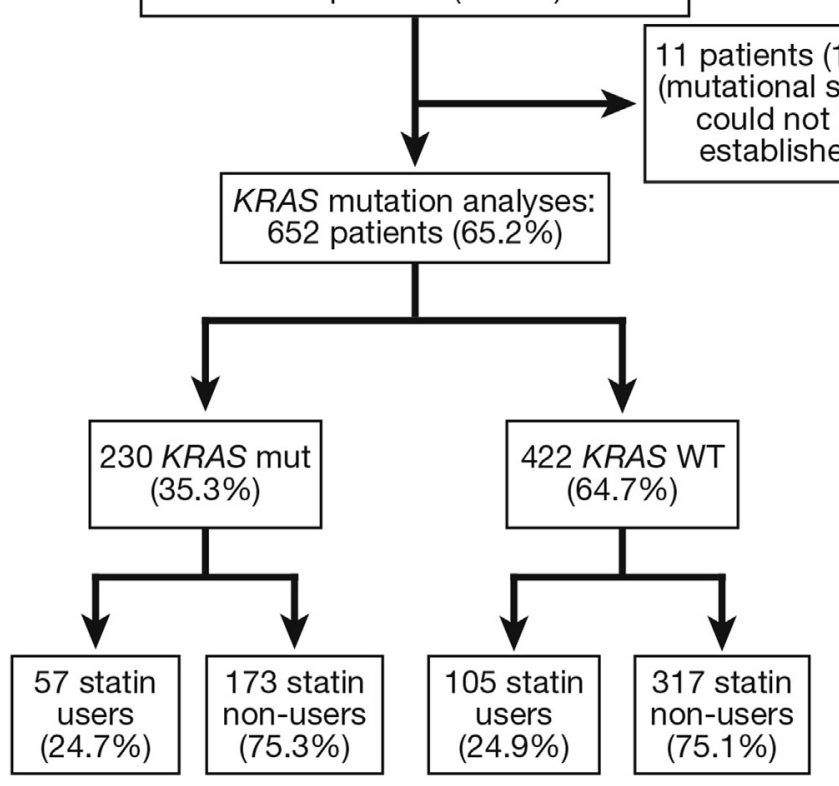

BMP pathway analysis

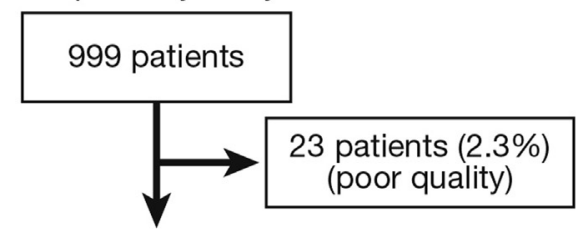

IHC scoring: 976 patients $(97.7 \%)$

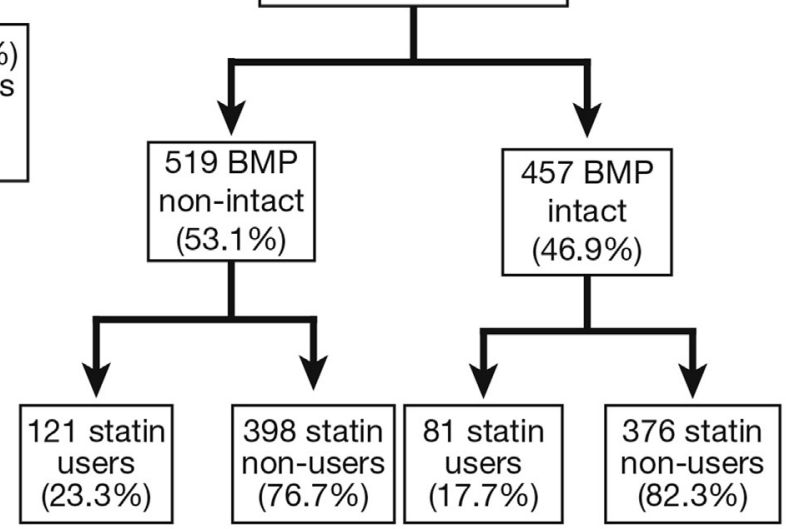

Figure 1. Flow diagram of the patient inclusion in the various analyses.

patients showed no discontinuation over the study period and $36.6 \%$ stopped for 30 days or less, which is not considered as discontinuation. Overall, $11.7 \%$ of the patients discontinued statin use for more than 30 days and $7 \%$ more than 90 days. Median follow-up of the cohort was 3.3 years (range, 0.01-8.27 years), with a median follow-up of 4.1 years (range, 0.001-7.94 years) for patients who were alive during the study period. Median first start of postdiagnosis statin use was at 1.9 years (range, 0.005-6.31 years). There were 396 deaths in 789 non-users of statins and 69 deaths in 210 patients who used statins.

The 5-year overall survival for non-users was $54.6 \%$ (95\% CI 50.8-58.1) and 65.7\% (95\% CI 57.8-72.4) for statin users. Statin use after diagnosis was significantly 
associated with a reduced risk of death from any cause with a rate ratio (RR) of $0.65(95 \% \mathrm{CI} 0.50-0.84, P=.001)$ and death from cancer; RR of 0.64 (95\% CI 0.47-0.85, $P=.002)$. When adjusted for potential confounders, this effect remained with an adjusted RR of 0.67 for overall survival (95\% CI 0.51-0.87, $P=.003$ ) and an adjusted RR of 0.66 for CSS $(95 \%$ CI $0.49-0.89, P=.007$ ) (Table 2). Supplementary Table 1 shows the RRs for variables used in the multivariable analyses other than statin use. Subgroup analyses by stage at diagnosis showed no association for mortality in stage I (adjusted RR 1.42; 95\% CI $0.50-4.02, P=.90$ ) and stage III (adjusted RR 1.10; 95\% CI $0.65-1.88, P=.71$ ), but showed an association between statin use and mortality for stage II (adjusted RR 0.45; $95 \% \mathrm{CI} 0.24-0.87, P=.02$ ) and stage IV (adjusted RR 0.43; $95 \%$ CI $0.25-0.76, P=.004$ ). The interaction test for mortality and stage is $P<.01$. Interestingly, frequent use of statins, especially more than 7 refills, further reduced

Table 2. Rate Ratio for Death (Time-Dependent Analysis Overall Mortality and Cancer-Specific Mortality), According to Use or Nonuse of Statin after Diagnosis

\begin{tabular}{|c|c|c|c|}
\hline $\begin{array}{c}\text { Statin } \\
\text { (all prescriptions) }\end{array}$ & $\begin{array}{c}\text { Statin } \\
\text { non-users }\end{array}$ & $\begin{array}{l}\text { Statin } \\
\text { users }^{a}\end{array}$ & $\begin{array}{c}P \\
\text { value }\end{array}$ \\
\hline Patients & 789 & 210 & \\
\hline Deaths from any cause & 396 & 69 & \\
\hline Rate ratio $(95 \% \mathrm{Cl})$ & 1.0 (reference) & $0.65(0.50-0.84)$ & .001 \\
\hline $\begin{array}{l}\text { Adjusted rate ratio } \\
\qquad(95 \% \mathrm{Cl})^{b}\end{array}$ & 1.0 (reference) & $0.67(0.51-0.87)$ & .003 \\
\hline Deaths from cancer & 311 & 53 & \\
\hline Rate ratio $(95 \% \mathrm{Cl})$ & 1.0 (reference) & $0.64(0.47-0.85)$ & .002 \\
\hline $\begin{array}{l}\text { Adjusted rate ratio } \\
\qquad(95 \% \mathrm{Cl})^{b}\end{array}$ & 1.0 (reference) & $0.66(0.49-0.89)$ & .007 \\
\hline \multicolumn{4}{|l|}{ Stage subgroups (CSS) } \\
\hline Stage I & 1.0 (reference) & $1.42(0.50-4.02)$ & .51 \\
\hline Stage II & 1.0 (reference) & $0.45(0.24-0.87)$ & .02 \\
\hline Stage III & 1.0 (reference) & $1.10(0.65-1.88)$ & .71 \\
\hline Stage IV & 1.0 (reference) & $0.43(0.25-0.76)$ & .004 \\
\hline \multicolumn{4}{|c|}{ Statin frequent use $\geq 3$ prescriptions } \\
\hline Patients & 802 & 197 & \\
\hline Deaths from cancer & 313 & 51 & \\
\hline Rate ratio $(95 \% \mathrm{Cl})$ & 1.0 (reference) & $0.63(0.47-0.85)$ & .002 \\
\hline $\begin{array}{l}\text { Adjusted rate ratio } \\
\qquad(95 \% \mathrm{Cl})^{b}\end{array}$ & 1.0 (reference) & $0.72(0.52-1.00)$ & .049 \\
\hline \multicolumn{4}{|c|}{ Statin frequent use ( $\geq 5$ prescriptions) } \\
\hline Patients & 815 & 184 & \\
\hline Deaths from cancer & 319 & 45 & \\
\hline Rate ratio $(95 \% \mathrm{Cl})$ & 1.0 (reference) & $0.57(0.42-0.78)$ & $<.001$ \\
\hline $\begin{array}{l}\text { Adjusted rate ratio } \\
\qquad(95 \% \mathrm{Cl})^{b}\end{array}$ & 1.0 (reference) & $0.65(0.46-0.91)$ & .012 \\
\hline \multicolumn{4}{|c|}{ Statin frequent use ( $\geq 7$ prescriptions) } \\
\hline Patients & 826 & 173 & \\
\hline Deaths from cancer & 322 & 42 & \\
\hline Rate ratio $(95 \% \mathrm{Cl})$ & 1.0 (reference) & $0.56(0.41-0.78)$ & $<.001$ \\
\hline $\begin{array}{l}\text { Adjusted rate ratio } \\
\qquad(95 \% \mathrm{Cl})^{b}\end{array}$ & 1.0 (reference) & $0.63(0.44-0.89)$ & .009 \\
\hline
\end{tabular}

\footnotetext{
${ }^{a}$ Statin use after diagnosis.

${ }^{b}$ Adjusted for sex, age, comorbidity, year of incidence, histologic grade, stage, microsatellite status, chemotherapy, and aspirin use.
}

risk of death, with an adjusted RR of 0.63 (95\% CI $0.44-0.89, P=.009$ ).

We have previously shown that low-dose aspirin use after diagnosis was associated with a survival benefit in this cohort. ${ }^{15}$ Therefore, we performed a further analysis in patients that only used statins or only used aspirin or a combination of both (Table 3). Compared with patients who used neither aspirin or statins after diagnosis, isolated statin use and isolated aspirin use were both significantly associated with a reduced risk of death from cancer, with an adjusted RR of $0.48(95 \%$ CI $0.31-0.73)$ for isolated statin use and 0.54 (95\% CI 0.35-0.85) for isolated aspirin use. A combination of both statin and aspirin use was not significantly associated with mortality; adjusted RR of 0.69 (95\% CI 0.46-1.03). The notion that statins act independently of aspirin use is further confirmed by the fact that statin use was significantly associated with a reduced risk of death in patients who did not use aspirin after diagnosis (adjusted RR $0.51,95 \%$ CI $0.33-0.79, P=.003$ ).

Including a lag of 6 months was associated with a reduced risk of death from cancer with a RR of $0.64(95 \% \mathrm{CI}$ $0.47-0.85, P=.002)$ and an adjusted RR of $0.66(95 \% \mathrm{CI}$ $0.48-0.89, P=.007)$.

\section{ACE Inhibitors and Benzodiazepines}

We performed sensitivity analyses with post-diagnosis ACE inhibitor, a group of cardiovascular medicines not associated with colon cancer survival, and observed a significant RR of 0.75 (95\% CI 0.59-0.96, $P=.024)$, but a nonsignificant adjusted RR of 0.81 (95\% CI $0.62-1.05, P=.114$ ). When excluding statin users, ACE inhibitor use has a RR of 0.98 (95\% CI $0.70-1.38, P=.93)$. We also analyzed a completely different class of drugs; benzodiazepines. These were not associated with improved survival $(P=.03)$.

\section{Statin use, Survival, and KRAS Mutations}

KRAS mutation status (wild-type/mutation) was established in $98 \%(652 / 663)$ of the tumor cores that were randomly taken from the 999 original tumor cores. There were no differences in baseline characteristics between

Table 3. Rate Ratio for Cancer-Specific Mortality (Time-Dependent Analysis), According to Aspirin or Statin Use

\begin{tabular}{|c|c|c|c|c|}
\hline & $\mathrm{N}$ & $\begin{array}{l}\text { Deaths } \\
\text { from } \\
\text { cancer }\end{array}$ & $\begin{array}{l}\text { Adjusted rate } \\
\text { ratio }(95 \% \mathrm{Cl})\end{array}$ & $\begin{array}{c}P \\
\text { value }\end{array}$ \\
\hline \multicolumn{5}{|l|}{ Aspirin or statin use } \\
\hline No aspirin or statin use & 711 & 288 & 1.0 (reference) & .0002 \\
\hline Statin use, no aspirin & 106 & 23 & $0.48(0.31-0.73)$ & \\
\hline Aspirin use, no statin & 78 & 23 & $0.54(0.35-0.85)$ & \\
\hline $\begin{array}{l}\text { Both aspirin and } \\
\text { statin use }\end{array}$ & 104 & 30 & $0.69(0.46-1.03)$ & \\
\hline \multicolumn{5}{|l|}{ Aspirin non-users } \\
\hline Statin non-users & 711 & 288 & 1.0 (reference) & .003 \\
\hline Statin users & 106 & 23 & $0.51(0.33-0.79)$ & \\
\hline
\end{tabular}


patients of whom the DNA was extracted and the KRAS mutation status was established and those in which this was not successful. A KRAS mutation was found in $35.3 \%$ (230/ 652 ) of the samples, which shows a prevalence that is in accord with other studies. ${ }^{17}$ Supplementary Table 2 summarizes the clinical characteristics of the patients based on the KRAS mutation status and statin use. Statin use was not significantly different in patients with KRAS wild-type tumors $(24.9 \%)$ and KRAS mutated tumors (24.8\%). The effect of KRAS mutation status on the survival benefit associated with statin use after diagnosis was analyzed. Statin use after diagnosis was not associated with a reduced risk of death from cancer in KRAS wild-type tumors (adjusted RR 0.82; 95\% CI $0.54-1.25, P=.35$ ) or KRAS mutated-tumors (adjusted RR 0.59; 95\% CI 0.33-1.08, $P=.086$ ); test for interaction $P=.4566$ (Table 4). A Cox proportional hazard model confirmed the results of the Poisson model (adjusted RR for KRAS mutant cancers, 0.64 ; 95\% CI 0.35-1.17, $P=.148$ ). An interaction analysis showed no statistically significant difference between the 2 molecular tumor subtypes $(P$ value for interaction $=.457)$. Supplementary Table 4 shows the results based on overall mortality.

\section{Statin use, Survival, and BMP Signaling}

Analysis of BMP signaling pathway components was performed on 976 tumor sections ( $97.7 \%$ of total). Loss of $2.3 \%$ of the tumor sections in this analysis was a consequence of staining artifacts and loss of material during the staining procedure. The tumors were categorized as having either "intact BMP signaling" or "non-intact BMP signaling" based on the expression levels of SMAD4 and the BMP receptors (see Materials and Methods section for a full description of the scoring system). We presumed that the BMP signaling pathway was intact when all components were expressed and that the BMP signaling pathway was "non-intact" when there was absence of expression of one of the components. In this cohort, 519 patients (53.2\%) showed non-intact BMP signaling in their tumor sections and 457 patients (46.8\%) showed intact BMP signaling. Supplementary Table 3 summarizes the clinical characteristics of the patients based on BMP signaling status and statin use; $23.3 \%$ of patients in whom we observed nonintact BMP signaling in the tumor sections were statin users and $17.7 \%$ of patients with intact BMP signaling were statin users. Statin users had more comorbidities in both groups. Within the "intact BMP signaling" group, low-stage tumors $(P=.012)$ were more prevalent in statin users than in statin non-users.

To test our hypothesis that statins act via the BMP pathway in colon cancer prevention, we analyzed the effect of BMP signaling pathway status on statin-associated patient survival (Table 4). The significant reduction in risk of death associated with statin use after diagnosis was more prominent in the group of tumors that exhibited intact BMP component expression with an adjusted RR of 0.39 (95\% CI $0.22-0.68, P=.001$ ) than for patients with tumors in which we observed a non-intact BMP signaling pathway (adjusted RR 0.81; 95\% CI $0.40-1.62, P=.55$ ). A Cox proportional
Table 4. Rate Ratio for Cancer-Specific Mortality (TimeDependent Analysis), According to Tumor KRAS Mutation Status ${ }^{e}$, BMP Signaling Pathway Status ${ }^{d}$ and Use or Non-use of Statin After Diagnosis

\begin{tabular}{|c|c|c|c|}
\hline & $\begin{array}{c}\text { Statin } \\
\text { non-users }\end{array}$ & $\begin{array}{l}\text { Statin } \\
\text { users }\end{array}$ & $\begin{array}{c}P \\
\text { value }\end{array}$ \\
\hline \multicolumn{4}{|l|}{ All cancers } \\
\hline Patients & 789 & 210 & \\
\hline Deaths from cancer & 311 & 53 & \\
\hline $\begin{array}{l}\text { Adjusted rate ratio } \\
(95 \% \mathrm{Cl})^{a, b}\end{array}$ & 1.0 (reference) & $0.66(0.49-0.89)$ & .007 \\
\hline $\begin{array}{l}\text { Adjusted hazard ratio } \\
(95 \% \mathrm{Cl})^{a, c}\end{array}$ & 1.0 (reference) & $0.71(0.53-0.97)$ & .032 \\
\hline \multicolumn{4}{|l|}{ KRAS Wild-type cancers } \\
\hline Patients & 317 & 105 & \\
\hline Deaths from cancer & 122 & 31 & \\
\hline $\begin{array}{l}\text { Adjusted rate ratio } \\
(95 \% \mathrm{Cl})^{a, b}\end{array}$ & 1.0 (reference) & $0.82(0.54-1.25)$ & .35 \\
\hline $\begin{array}{c}\text { Adjusted hazard ratio } \\
(95 \% \mathrm{Cl})^{a, c}\end{array}$ & 1.0 (reference) & $0.86(0.56-1.31)$ & .48 \\
\hline \multicolumn{4}{|l|}{ KRAS Mutant cancers } \\
\hline Patients & 173 & 57 & \\
\hline Deaths from cancer & 74 & 15 & \\
\hline $\begin{array}{l}\text { Adjusted rate ratio } \\
(95 \% \mathrm{Cl})^{a, b}\end{array}$ & 1.0 (reference) & $0.59(0.33-1.08)$ & .086 \\
\hline $\begin{array}{l}\text { Adjusted hazard ratio } \\
(95 \% \mathrm{Cl})^{a, c}\end{array}$ & 1.0 (reference) & $0.64(0.35-1.17)$ & .148 \\
\hline \multicolumn{4}{|l|}{ Intact BMP-signaling } \\
\hline Patients & 376 & 81 & \\
\hline Deaths from cancer & 124 & 18 & \\
\hline $\begin{array}{l}\text { Adjusted rate ratio } \\
(95 \% \mathrm{Cl})^{a, b}\end{array}$ & 1.0 (reference) & $0.39(0.22-0.68)$ & .001 \\
\hline $\begin{array}{l}\text { Adjusted hazard ratio } \\
(95 \% \mathrm{Cl})^{a, c}\end{array}$ & 1.0 (reference) & $0.42(0.24-0.74)$ & .003 \\
\hline \multicolumn{4}{|l|}{ Non-intact BMP-signaling } \\
\hline Patients & 398 & 121 & \\
\hline Deaths from cancer & 179 & 33 & \\
\hline $\begin{array}{l}\text { Adjusted rate ratio } \\
(95 \% \mathrm{Cl})^{a, b}\end{array}$ & 1.0 (reference) & $0.81(0.55-1.21)$ & .31 \\
\hline $\begin{array}{l}\text { Adjusted hazard ratio } \\
(95 \% \mathrm{Cl})^{a, c}\end{array}$ & 1.0 (reference) & $0.89(0.60-1.33)$ & .58 \\
\hline \multicolumn{4}{|c|}{ Intact BMP-signaling and wild-type cancers } \\
\hline Patients & 150 & 44 & \\
\hline Deaths from cancer & 43 & 12 & \\
\hline $\begin{array}{l}\text { Adjusted rate ratio } \\
(95 \% \mathrm{Cl})^{a, b}\end{array}$ & 1.0 (reference) & $0.81(0.40-1.62)$ & .55 \\
\hline \multicolumn{4}{|c|}{ Intact BMP-signaling and mutant cancers } \\
\hline Patients & 89 & 18 & \\
\hline Deaths from cancer & 34 & 6 & \\
\hline Adjusted rate ratio & 1.0 (reference) & $0.59(0.22-1.57)$ & .29 \\
\hline
\end{tabular}

\footnotetext{
${ }^{a}$ Adjusted for sex, age, comorbidity, year of incidence, histologic grade, stage, microsatellite status, and chemotherapy. ${ }^{b}$ Poisson model.

${ }^{c}$ Cox model.

dKRAS analyses: 663 of 999 patients analysed; 652 of 663 samples included.

${ }^{e}$ BMP analyses: 976 of 999 samples included.
}

hazard model confirmed the results of the Poisson model (adjusted RR 0.42; 95\% CI 0.24-0.74, $P=.003$ ). An interaction analysis showed a statistically significant difference between the 2 molecular tumor subtypes $(P$ value for 
interaction <.001). Supplementary Table 4 shows the results based on overall mortality.

\section{Discussion}

In this large observational study, we show in our cohort that statin use initiated or continued after a diagnosis of colon cancer is associated with a significantly reduced risk of death from any cause with an RR of 0.65 and death from cancer with an RR of 0.64 . To test for associations between the molecular tumor subtype and the effect of statins on colon cancer survival, we analyzed both the KRAS mutation status and the protein expression of multiple elements of the BMP signaling pathway in the tumor samples. We have previously performed similar analyses of the BMP pathway in both pancreatic ductal adenocarcinoma and colorectal cancer. ${ }^{16,18}$ We found that the association between statins and survival did not differ in KRAS mutant versus KRAS wildtype tumor, but the survival benefit associated with statin use was stronger in tumors with an intact BMP signaling pathway. This is in accordance with findings from our previous in vitro and rodent studies showing that statins are only effective antitumor agents in tumors where the BMP signaling pathway is functional. ${ }^{7,11}$

Statins may be an attractive candidate for use as adjuvant therapy in colorectal cancer because they are already widely used and well tolerated. ${ }^{19,20}$ Statins have previously been shown to reduce the incidence of colorectal cancer. A large retrospective study published in 2005 assessing the association between statin use and the incidence of colorectal cancer showed a $47 \%$ reduction in the risk of developing colorectal cancer. ${ }^{5}$ Although several subsequent studies have failed to confirm this effect, ${ }^{21,22}$ a recent metaanalysis combining 42 large observational studies, casecontrol studies, and randomized control trials showed an overall risk reduction of $10 \%$ for the development of colorectal cancer in statin users, providing more evidence for the antitumor potential of statins. ${ }^{23}$

Despite the large number of trials that have investigated the association between the incidence of colorectal cancer and statin use, relatively few studies have investigated the effect of adjuvant statin use on patient survival in colorectal cancer. A study from Scotland that included 308 patients with colorectal cancer found a non-significant reduction in colorectal cancer-specific mortality in statin users. ${ }^{24}$ An American study of 407 patients with rectal cancer who received chemo-radiotherapy also found a non-significant reduction in cancer-specific mortality in statin users before and after surgery. ${ }^{25}$ Another American study in 842 patients with stage III colon cancer did not detect any association between patient-reported statin use after diagnosis and cancer recurrence ${ }^{26}$; and a Dutch study found no association between statin use, KRAS mutation status, and metastatic colorectal cancer progression-free survival after chemotherapy. ${ }^{27}$ Some of these studies investigated specific colorectal cancer subgroups ${ }^{25-27}$ or had limitations, such as relatively small size ${ }^{24-27}$ measurement of medication use at 1 time-point, ${ }^{26}$ and potential for immortal time bias. ${ }^{24}$ In the biggest study to date from the UK, a cohort of 7657 patients with colorectal cancer were analyzed using time-dependent Cox regression models. Statin use post-diagnosis was associated with a significant reduction in overall survival. ${ }^{28}$ This is consistent with our findings of a strong association between statin use and overall patient survival. The strengths of our study are the use of registered drug prescriptions to ascertain drug exposure rather than patient questionnaires, a relatively large cohort of 999 patients, molecular analysis of tumor tissue, and analysis of the effect of combined exposure to aspirin and statins. This is particularly interesting in the light of conflicting evidence as to whether a combination of aspirin and statins may be more effective than one or the other alone. ${ }^{29-32}$

A recently published study with this cohort showed an association between low-dose aspirin use after diagnosis and improved survival. ${ }^{15}$ Interestingly, isolated use of either statins or aspirin after diagnosis are both associated with an improved survival in patients, indicating that statins and aspirin improve patient outcome independently. Although there is considerable in vitro evidence that a combined therapy of statins and aspirin could be beneficial, ${ }^{33}$ we could not find a synergistic or additive effect of statin combined with aspirin use. Separating this cohort based on statin and/or aspirin use results in a relative small number of patients per group; a larger cohort will be needed to assess the additive effect of combination therapy.

The molecular mechanisms responsible for the antitumor effects of statins on colorectal cancer are not fully understood. As mentioned in our introduction, several mechanisms have been proposed, 2 of which we have investigated in this study, namely that statins act on KRAS by influencing its prenylation and that statins act by activating the BMP signaling pathway.

Firstly, we investigated the influence of KRAS mutation status on the association between statin use and patient survival. There is evidence that statins act through the inhibition of the Ras/Raf pathway from studies performed in cancer cell line cells and xenograft mouse models. For example, it has been shown that lovastatin inhibits the Raf/ MEK/ERK pathway in leukemia cells, resulting in apoptosis, $^{34}$ and that atorvastatin can disrupt KRAS/Raf complexes, leading to inhibition of AKT and ERK in nonsmall cell lung cancer cells. ${ }^{35}$ The most clinically relevant data came from a study showing that simvastatin could overcome cetuximab resistance in colon cancer cell line cells harboring KRAS mutations and not in cells with BRAF mutations, implying that only KRAS mutant cancers would benefit from statin treatment. ${ }^{36}$ We did not see a difference in the association between statin and survival comparing KRAS WT cancers and KRAS mutant cancers in our cohort. There was no significant reduction in risk of death associated with statin use in either group, although the results in KRAS mutant tumors nearly reached significance. The reason for the loss of a significant protective effect of statins when separating the cancers based on the KRAS mutation status is probably the low number of cancers in each group. A larger cohort is therefore necessary to adequately assess the influence of $K R A S$ mutation status on the survival benefit associated with statin use. Our data is consistent with 2 
studies that have found no association between the KRAS mutation status, statin use, and colorectal cancer survival. $^{26,27}$ However, in these studies, statin use after diagnosis was not associated with improved survival in colorectal cancer overall, in contrast to our study, making the studies difficult to compare.

Secondly, we investigated the influence of tumor expression of elements of the BMP signaling pathway on the association between statin use and patient survival. The BMP signaling pathway functions as a tumor suppressor in colorectal cancer, inducing cell differentiation and apoptosis of colonic epithelial cells and negatively regulating WNT signaling. ${ }^{37,38}$ In a screen of 30,000 compounds, lovastatin and simvastatin were the 2 most potent enhancers of BMP2 expression in bone. ${ }^{10}$ We have subsequently shown that statins inhibit colorectal cancer cell proliferation and induce apoptosis through increasing BMP2 expression, but only when the BMP pathway is fully functional. ${ }^{7}$ BMP ligands bind to a complex of transmembrane serine threonine kinase receptors type 1 and 2, resulting in phosphorylation and activation of the BMP receptor type 2 (BMPR2). The activated BMPR2 activates BMP receptor type 1 (BMPR1a and BMPR1b), which phosphorylate the receptor-associated SMADS (SMAD1, 5, and 8) that subsequently complex with SMAD4 and translocate to the nucleus to regulate gene transcription. When expression of either SMAD4 or any one of the BMP receptors is lost, the canonical BMP signaling pathway cannot be activated. We assessed the expression levels of SMAD4, BMPR1a, BMPR1b, and BMPR2 using immunohistochemistry as we have performed previously. In this cohort, statins are associated with a reduced risk of death in cancers that express both SMAD4 and BMP receptors (described in the Results section as intact BMP signaling), suggesting that the anticancer benefit of statin may be BMP-dependent. Because this is the first study to investigate the role of the BMP signaling pathway in the association between statins and colon cancer mortality, comparison with other studies is not possible. These results require confirmation in further cohorts.

There are several limitations to the study. This is a retrospective study in which randomization was not possible. Immortal time bias was avoided by using a timedependent model, but confounding by disease progression may still occur. Next to a parametric survival model with exponential (Poisson) distribution, a Cox proportional hazard model was used with statin use as a time varying covariate to confirm the analyses. Our methodology for defining user and non-user time will minimize confounding by disease progression. This can arise where poor prognosis or advanced disease influences statin usage, with statins being stopped in these patients potentially leading to a spuriously lower number of deaths in statin users. This depends on how "statin user" is defined and how statin user time is accrued. In our study, user time is accrued after the first prescription, even if a patient subsequently stopped using statins, effectively avoiding this bias.

Reverse causation was further addressed by applying a lag of exposure of 6 months, which also resulted in a significant difference.
Because reduced risk of death could potentially be explained by reductions in cardiovascular events in statin users, we also analyzed risk of death from any cause. Statin use can also be a sign of compliance. Consistent statin use could therefore be a surrogate marker for health consciousness, which can cause a "healthy user bias" in studies like ours. We observed similar effects of aspirin and statins on colon cancer mortality, implying that both medications are protective or that a hidden factor connecting aspirin and statins is responsible. However, analyses with ACE inhibitors and benzodiazepines proved that this was not the case.

There were differences in baseline characteristics between statin users and statin non-users that could have confounded our results: statin users were more often male, were older, had more comorbidity, and had earlier stage tumors. However, when adjusting for these confounders, a clear association between statin use and a better prognosis remained. However, residual confounding by unknown factors could still influence the results. Lastly, the assessment of active BMP signaling is not perfect. The fact that all the components of BMP signaling are present or the fact 1 or more components are missing does not necessarily mean that there is or isn't active BMP signaling. Because of the complex matrix of downstream signaling targets, which can be activated or inhibited by canonical and/or noncanonical BMP signaling, it is difficult to find a suitable (surrogate marker) for BMP signaling activity. Phospho-SMAD1, 5, or 8 are commonly used in vitro to determine BMP signaling activity, but phospho-proteins are very sensitive to tissue processing and fixation, making the assessment of expression levels in human tissue inaccurate. ${ }^{39}$ In another study using human colon cancer tissue, we found nuclear p-SMAD1, 5, or 8 without the presence of SMAD4, which is thought to be necessary for nuclear translocation of p-SMAD1, 5, or 8. We cannot evaluate whether this is the result of tissue processing or SMAD4-independent non-canonical BMP signaling. We do know that loss of SMAD4 in colon cancer is associated with a poor patient survival and negative nuclear p-SMAD1, 5, or 8 staining is not. ${ }^{39}$

In conclusion, in our cohort statin use after diagnosis is associated with a reduced risk of death in patients with colon cancer. More importantly, this reduction was most pronounced in patients whose tumors retain expression of BMP signaling pathway components. In the future, BMP signaling functionality may serve as a predictive biomarker to select patients for adjuvant statin therapy. However, our data are preliminary and other studies, preferably randomized clinical trials, are needed to confirm the beneficial effects of statins on colon cancer survival and BMP signaling as a predictive biomarker.

\section{Supplementary Material}

Note: To access the supplementary material accompanying this article, visit the online version of Gastroenterology at www.gastrojournal.org, and at http://dx.doi.org/10.1053/ j.gastro.2017.05.011. 


\section{References}

1. Howlader N, Noone NA, Krapcho M, et al, eds. SEER cancer statistics review, 1975-2010. Bethesda, MD: National Cancer Institute, April 2013. Available at: http:// seer.cancer.gov/csr/1975_2010/.

2. Bastiaannet E, Sampieri K, Dekkers OM, et al. Use of aspirin postdiagnosis improves survival for colon cancer patients. BR J Cancer 2012;106:1564-1570.

3. Chan AT, Ogino S, Fuchs CS. Aspirin use and survival after diagnosis of colorectal cancer. JAMA 2009; 302:649-658.

4. Downs JR, Clearfield M, Tyroler HA, et al. Air Force/ Texas Coronary Atherosclerosis Prevention Study (AFCAPS/TEXCAPS): additional perspectives on tolerability of long-term treatment with lovastatin. Am J Cardiol 2001;87:1074-1079.

5. Poynter JN, Gruber SB, Higgins PD, et al. Statins and the risk of colorectal cancer. N Engl J Med 2005;352: 2184-2192.

6. Agarwal B, Halmos B, Feoktistov AS, et al. Mechanism of lovastatin-induced apoptosis in intestinal epithelial cells. Carcinogenesis 2002;23:521-528.

7. Kodach LL, Bleuming SA, Peppelenbosch MP, et al. The effect of statins in colorectal cancer is mediated through the bone morphogenetic protein pathway. Gastroenterology 2007;133:1272-1281.

8. Konstantinopoulos PA, Karamouzis MV, Papavassiliou AG. Post-translational modifications and regulation of the RAS superfamily of GTPases as anticancer targets. Nat Rev Drug Discov 2007;6:541-555.

9. Baldus SE, Schaefer KL, Engers R, et al. Prevalence and heterogeneity of KRAS, BRAF, and PIK3CA mutations in primary colorectal adenocarcinomas and their corresponding metastases. Clin Cancer Res 2010;16:790-799.

10. Mundy G, Garrett R, Harris S, et al. Stimulation of bone formation in vitro and in rodents by statins. Science 1999;286:1946-1949.

11. Kodach LL, Jacobs RJ, Voorneveld PW, et al. Statins augment the chemosensitivity of colorectal cancer cells inducing epigenetic reprogramming and reducing colorectal cancer cell 'stemness' via the bone morphogenetic protein pathway. Gut 2011;60:1544-1553.

12. Hardwick JC, Kodach LL, Offerhaus GJ, van den Brink GR. Bone morphogenetic protein signalling in colorectal cancer. Nat Rev Cancer 2008;8:806-812.

13. Kodach LL, Wiercinska E, de Miranda NF, et al. The bone morphogenetic protein pathway is inactivated in the majority of sporadic colorectal cancers. Gastroenterology 2008;134:1332-1341.

14. van Herk-Sukel MP, van de Poll-Franse LV, Lemmens VE, et al. New opportunities for drug outcomes research in cancer patients: the linkage of the Eindhoven Cancer Registry and the PHARMO Record Linkage System. Eur J Cancer 2010;46:395-404.

15. Reimers MS, Bastiaannet E, Langley RE, et al. Expression of HLA class I antigen, aspirin use, and survival after a diagnosis of colon cancer. JAMA 2014;174:732-739.

16. Voorneveld PW, Kodach LL, Jacobs RJ, et al. Loss of SMAD4 alters BMP signaling to promote colorectal cancer cell metastasis via activation of Rho and ROCK. Gastroenterology 2014;147:196-208.

17. Yoon HH, Tougeron D, Shi Q, et al. KRAS codon 12 and 13 mutations in relation to disease-free survival in BRAFwild-type stage III colon cancers from an adjuvant chemotherapy trial (N0147 alliance). Clin Cancer Res 2014;20:3033-3043.

18. Voorneveld PW, Stache V, Jacobs RJ, et al. Reduced expression of bone morphogenetic protein receptor IA in pancreatic cancer is associated with a poor prognosis. Br J Cancer 2013;109:1805-1812.

19. Downs JR, Clearfield M, Weis S, et al. Primary prevention of acute coronary events with lovastatin in men and women with average cholesterol levels. JAMA 1998; 279:1615-1622.

20. Nissen SE, Tuzcu EM, Schoenhagen P, et al. Statin therapy, LDL cholesterol, C-reactive protein, and coronary artery disease. N Engl J Med 2005;352:29-38.

21. Coogan PF, Smith J, Rosenberg L. Statin use and risk of colorectal cancer. J Natl Cancer Inst 2007;99:32-40.

22. Jacobs EJ, Newton CC, Thun MJ, Gapstur SM. Longterm use of cholesterol-lowering drugs and cancer incidence in a large United States cohort. Cancer Res 2011;71:1763-1771.

23. Liu Y, Tang W, Wang J, et al. Association between statin use and colorectal cancer risk: a meta-analysis of 42 studies. Cancer Causes Control 2014;25:237-249.

24. Lakha F, Theodoratou E, Farrington SM, et al. Statin use and association with colorectal cancer survival and risk: case control study with prescription data linkage. BMC Cancer 2012;12:487.

25. Mace AG, Gantt GA, Skacel M, et al. Statin therapy is associated with improved pathologic response to neoadjuvant chemoradiation in rectal cancer. Dis Colon Rectum 2013;56:1217-1227.

26. $\mathrm{Ng} \mathrm{K,} \mathrm{Ogino} \mathrm{S,} \mathrm{Meyerhardt} \mathrm{JA,} \mathrm{et} \mathrm{al.} \mathrm{Relationship}$ between statin use and colon cancer recurrence and survival: results from CALGB 89803. J Natl Cancer Inst 2011;103:1540-1551.

27. Krens LL, Simkens LHJ, Baas JM, et al. Statin use is not associated with improved progression free survival in cetuximab treated KRAS mutant metastatic colorectal cancer patients: results from the CAIRO2 Study. PLoS ONE 2014;9:e112201.

28. Cardwell CR, Hicks BM, Hughes C, et al. Statin use after colorectal cancer diagnosis and survival: a populationbased cohort study. J Clin Oncol 2014;32:3177-3183.

29. Vinogradova Y, Hippisley-Cox J, Coupland C, et al. Risk of colorectal cancer in patients prescribed statins, nonsteroidal anti-inflammatory drugs, and cyclooxygenase-2 inhibitors: nested case-control study. Gastroenterology 2007;133:393-402.

30. Hoffmeister M, Chang-Claude J, Brenner H. Individual and joint use of statins and low-dose aspirin and risk of colorectal cancer: a population-based case-control study. Int J Cancer 2007;121:1325-1330.

31. Shadman M, Newcomb PA, Hampton JM, et al. Nonsteroidal anti-inflammatory drugs and statins in relation to colorectal cancer risk. World J Gastroenterol 2009; 15:2336-2339. 
32. Agarwal B, Rao CV, Bhendwal S, et al. Lovastatin augments sulindac-induced apoptosis in colon cancer cells and potentiates chemopreventive effects of sulindac. Gastroenterology 1999;117:838-847.

33. Xiao H, Yang CS. Combination regimen with statins and NSAIDs: a promising strategy for cancer chemoprevention. Int J Cancer 2008;123:983-990.

34. Wu J, Wong WW, Khosravi F, et al. Blocking the Raf/ MEK/ERK pathway sensitizes acute myelogenous leukemia cells to lovastatin-induced apoptosis. Cancer Res 2004;64:6461-6468.

35. Chen J, Bi H, Hou J, et al. Atorvastatin overcomes gefitinib resistance in KRAS mutant human non-small cell lung carcinoma cells. Cell Death Dis 2013;4:e814.

36. Lee J, Lee I, Han B, et al. Effect of simvastatin on cetuximab resistance in human colorectal cancer with KRAS mutations. J Natl Cancer Inst 2011;103:674-688.

37. Hardwick JC, van den Brink GR, Bleuming SA, et al. Bone morphogenetic protein 2 is expressed by, and acts upon, mature epithelial cells in the colon. Gastroenterology 2004;126:111-121.
38. He XC, Zhang J, Tong WG, et al. BMP signaling inhibits intestinal stem cell self-renewal through suppression of Wnt-beta-catenin signaling. Nat Genet 2004;36: 1117-1121.

39. Voorneveld PW, Jacobs RJ, De Miranda NF, et al. Evaluation of the prognostic value of PSMAD immunohistochemistry in colorectal cancer. eur J Cancer Prev 2013; 22:420-424.

Author names in bold designate shared co-first authors.

Received April 15, 2015. Accepted May 8, 2017.

Reprint requests

Address requests for reprints to: James C. H. Hardwick, MD, PhD Department of Gastroenterology and Hepatology, Leiden University Medical Centre, Albinusdreef 2, 2300RC Leiden, The Netherlands. e-mail: j.c.h.hardwick@lumc.nl; fax: +3171 5248115.

Conflicts of interest

The authors disclose no conflicts.

Funding

J.C.H.H. is funded by the Dutch Digestive Diseases Foundation. G.J.L. is funded by the Sloos-Alandt family. 

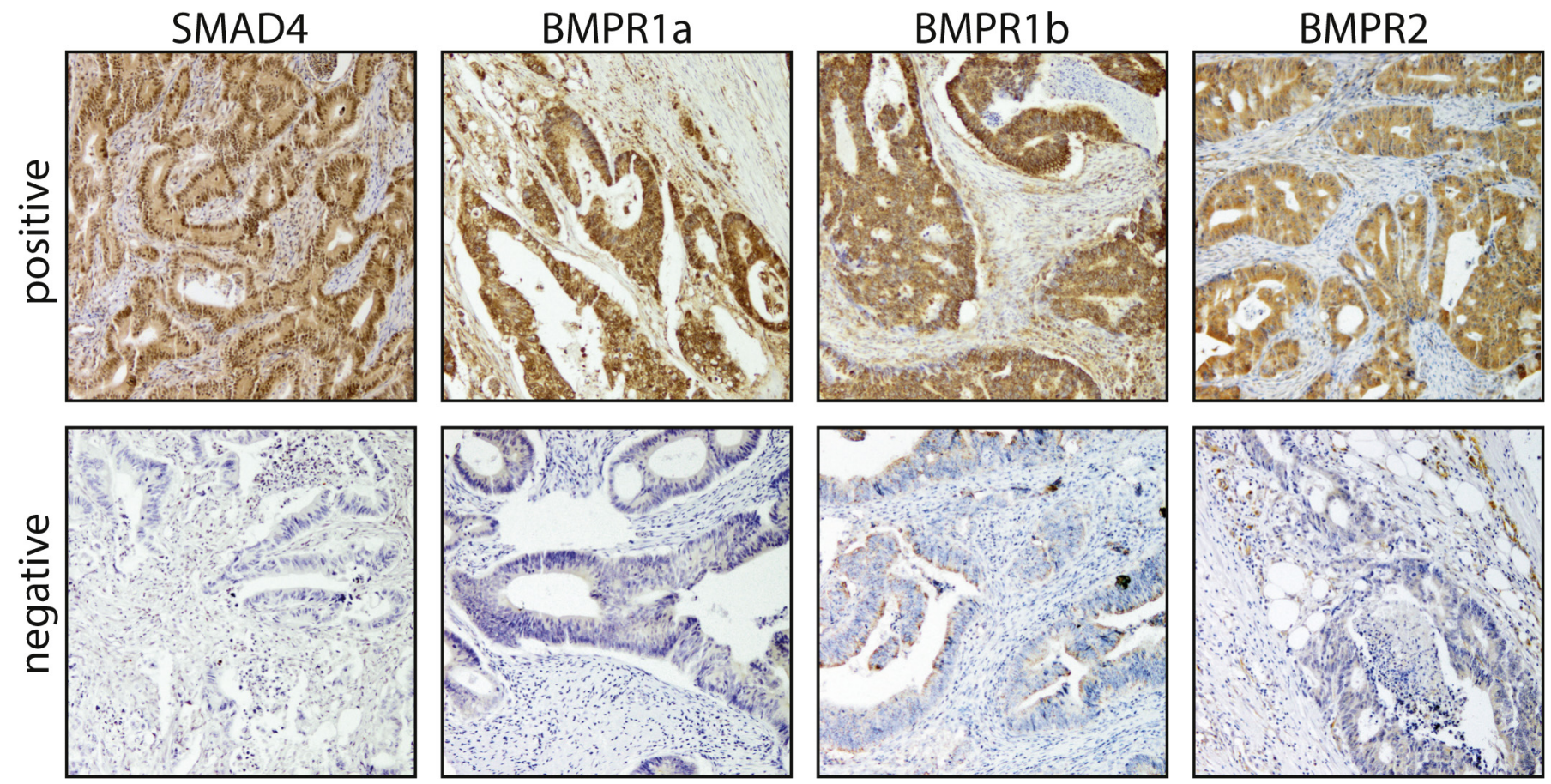

Supplementary Figure 1. Immunohistochemistry for SMAD4, BMPR1a, BMPR1b \& BMPR2 in 567 human colon cancer. Representative cores that show positive or negative expression. 
Supplementary Table 1. Rate Ratio for Cancer Specific Mortality (Time-Dependent Analysis) for Variables other than Statin Use

\begin{tabular}{lccc}
\hline Multivariable model & Reference category & Rate ratio & $P$ value \\
\hline Sex & 1.0 (male) & $0.84(0.67-1.04)$ & .10 \\
Age & 1.0 (continuous) & $1.04(1.03-1.06)$ & $1.39(1.10-1.77)$ \\
Comorbidity & 1.0 (no comorbidity) & $1.02(0.95-1.08)$ & .001 \\
Incidence year & 1.0 (continuous) & $1.21(0.80-1.84)$ grade II & .60 \\
Grade & 1.0 (grade I) & $2.29(1.47-3.57)$ grade III & $<.001$ \\
& & $1.21(0.70-2.08)$ unknown grade & $1.53(0.94-2.51)$ stage II \\
Stage & 1.0 (stage I) & $3.80(2.31-6.27)$ stage III \\
& & $22.93(13.93-37.74)$ stage IV \\
& & $3.15(0.42-23.89)$ unknown stage \\
Microsatellite status & 1.0 (negative) & $0.93(0.63-1.37)$ & $0.69(0.52-0.90)$ \\
Chemotherapy & 1.0 (no) & $0.69(0.50-0.95)$ \\
Aspirin use & 1.0 (no) & \\
\end{tabular}

Supplementary Table 2. Baseline Characteristics of the Colon Cancer Patients according to KRAS and Use of Statin After Diagnosis. Overall statin use: 210 patients (21.0\%)

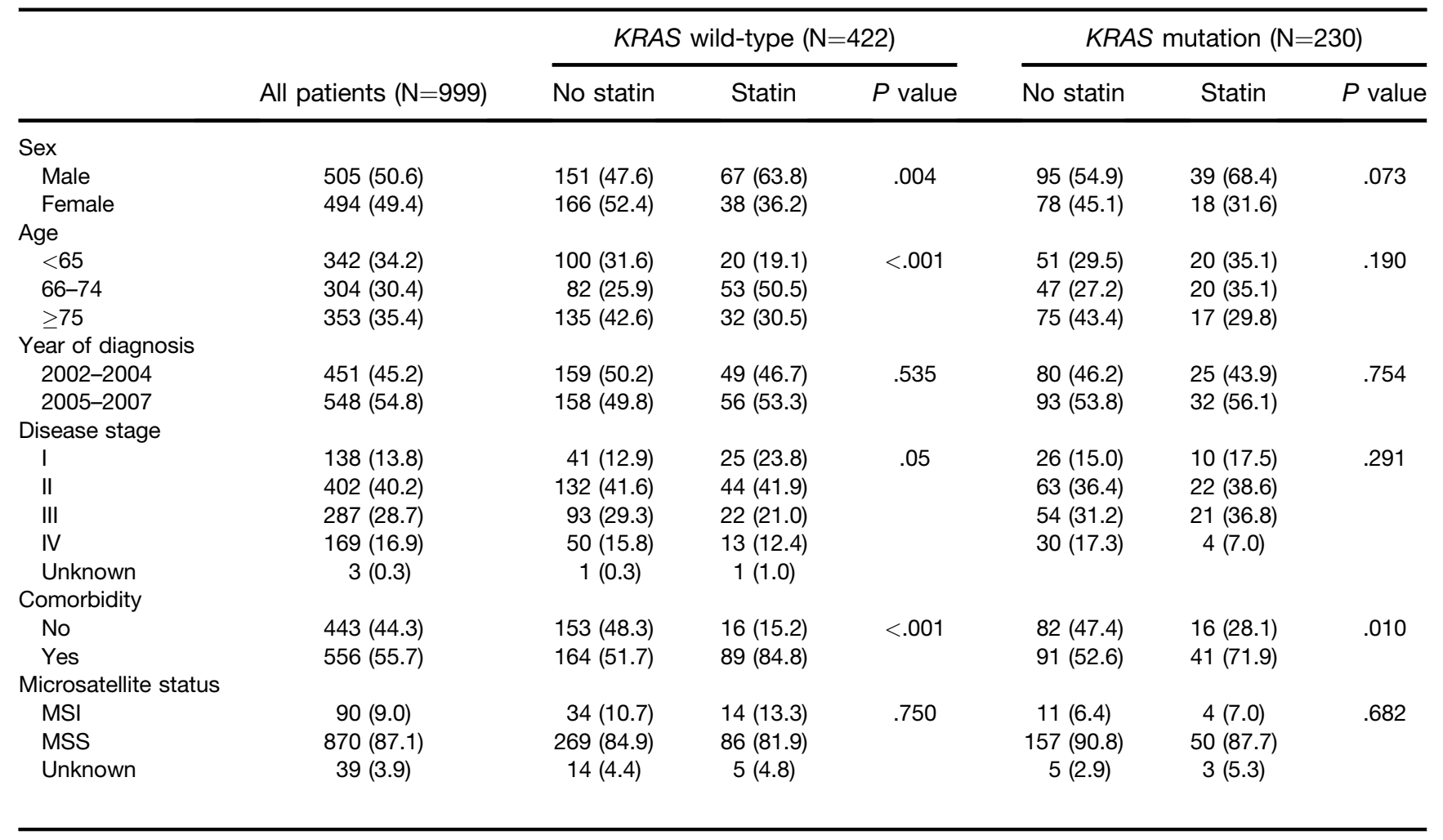

MSI, microsatellite instable tumors; MSS, microsatellite stable tumors. 
Supplementary Table 3. Baseline Characteristics of the Colon Cancer Patients According to Intact BMP Signaling and Use of Statin After Diagnosis

\begin{tabular}{|c|c|c|c|c|c|c|c|}
\hline & \multirow[b]{2}{*}{ All patients $(\mathrm{N}=999)$} & \multicolumn{3}{|c|}{ Non-intact BMP signaling $(\mathrm{N}=519)$} & \multicolumn{3}{|c|}{ Intact BMP signaling $(\mathrm{N}=457)$} \\
\hline & & No statin & Statin & $P$ value & No statin & Statin & $P$ value \\
\hline Male & $505(50.6)$ & $195(49.0)$ & $73(60.3)$ & \multirow[t]{2}{*}{.029} & $178(47.3)$ & 48 (59.3) & \multirow[t]{2}{*}{.052} \\
\hline Female & $494(49.4)$ & $203(51.0)$ & $48(39.7)$ & & $198(52.7)$ & $33(40.7)$ & \\
\hline \multicolumn{8}{|l|}{ Age } \\
\hline$\geq 75$ & $353(35.4)$ & $155(38.9)$ & $29(24.0)$ & .001 & $135(35.9)$ & $23(28.4)$ & $<.001$ \\
\hline \multicolumn{8}{|c|}{ Year of diagnosis } \\
\hline 2002-2004 & $451(45.2)$ & $188(47.2)$ & $56(46.3)$ & \multirow[t]{2}{*}{.854} & $155(41.2)$ & $36(44.4)$ & \multirow[t]{2}{*}{.594} \\
\hline 2005-2007 & $548(54.8)$ & $210(52.8)$ & $65(53.7)$ & & $221(58.8)$ & $45(55.6)$ & \\
\hline \multicolumn{8}{|l|}{ Disease stage } \\
\hline I & $138(13.8)$ & $44(11.1)$ & $20(16.5)$ & .055 & $52(13.8)$ & $17(21.0)$ & .012 \\
\hline \multicolumn{8}{|l|}{ Comorbidity } \\
\hline No & $443(44.3)$ & $205(51.5)$ & $26(21.5)$ & \multirow[t]{2}{*}{$<.001$} & $188(50.0)$ & $16(19.8)$ & \multirow[t]{2}{*}{$<.001$} \\
\hline Yes & $556(55.7)$ & $193(48.5)$ & $95(78.5)$ & & $188(50.0)$ & $65(80.3)$ & \\
\hline \multicolumn{8}{|c|}{ Microsatellite status } \\
\hline MSI & $90(9.0)$ & $34(8.5)$ & $10(8.3)$ & \multirow[t]{3}{*}{.425} & $35(9.3)$ & $10(12.4)$ & \multirow[t]{3}{*}{.628} \\
\hline MSS & $870(87.1)$ & $356(89.5)$ & $106(87.6)$ & & $333(88.6)$ & $70(86.4)$ & \\
\hline Unknown & $39(3.9)$ & $8(2.0)$ & $5(4.1)$ & & $8(2.1)$ & $1(1.2)$ & \\
\hline
\end{tabular}

MSI, microsatellite instable tumors; MSS, microsatellite stable tumors. 
Supplementary Table 4.Time-Dependent Analysis Overall Mortality, According to Tumor KRAS Mutation Status, BMP

Signaling Pathway Status, and Use or Non-use of Statin after Diagnosis

\begin{tabular}{|c|c|c|c|}
\hline & $\begin{array}{c}\text { Statin } \\
\text { non-users }\end{array}$ & $\begin{array}{l}\text { Statin } \\
\text { users }^{a}\end{array}$ & $\begin{array}{c}P \\
\text { value }\end{array}$ \\
\hline \multicolumn{4}{|l|}{ All Cancers } \\
\hline Patients & 789 & 210 & \\
\hline Deaths & 396 & 69 & \\
\hline $\begin{array}{l}\text { Adjusted rate ratio } \\
(95 \% \mathrm{Cl})^{b, c}\end{array}$ & 1.0 (reference) & $0.67(0.51-0.87)$ & .003 \\
\hline $\begin{array}{l}\text { Adjusted hazard } \\
\text { ratio }(95 \% \mathrm{Cl})^{b, d}\end{array}$ & 1.0 (reference) & $0.68(0.53-0.90)$ & .007 \\
\hline \multicolumn{4}{|l|}{ KRAS Wild-type cancers } \\
\hline Patients & 317 & 105 & \\
\hline Deaths & 162 & 40 & \\
\hline $\begin{array}{l}\text { Adjusted rate } \\
\text { ratio }(95 \% \mathrm{Cl})^{b, c}\end{array}$ & 1.0 (reference) & $0.81(0.56-1.18)$ & .273 \\
\hline $\begin{array}{l}\text { Adjusted hazard } \\
\text { ratio }(95 \% \mathrm{Cl})^{b, d}\end{array}$ & 1.0 (reference) & $0.85(0.59-1.23)$ & .390 \\
\hline \multicolumn{4}{|l|}{ KRAS Mutant cancers } \\
\hline Patients & 173 & 57 & \\
\hline Deaths & 89 & 18 & \\
\hline $\begin{array}{l}\text { Adjusted rate } \\
\text { ratio }(95 \% \mathrm{Cl})^{b, c}\end{array}$ & 1.0 (reference) & $0.59(0.35-1.03)$ & .062 \\
\hline $\begin{array}{l}\text { Adjusted hazard } \\
\text { ratio }(95 \% \mathrm{Cl})^{b, d}\end{array}$ & 1.0 (reference) & $0.59(0.34-1.03)$ & .065 \\
\hline \multicolumn{4}{|l|}{ Intact BMP signaling } \\
\hline Patients & 376 & 81 & \\
\hline Deaths & 158 & 24 & \\
\hline $\begin{array}{l}\text { Adjusted rate } \\
\text { ratio }(95 \% \mathrm{Cl})^{b, c}\end{array}$ & 1.0 (reference) & $0.46(0.29-0.74)$ & .001 \\
\hline $\begin{array}{l}\text { Adjusted hazard } \\
\text { ratio }(95 \% \mathrm{Cl})^{b, d}\end{array}$ & 1.0 (reference) & $0.49(0.31-0.79)$ & .003 \\
\hline \multicolumn{4}{|c|}{ Non-intact BMP signaling } \\
\hline Patients & 398 & 121 & \\
\hline Deaths & 229 & 42 & \\
\hline $\begin{array}{l}\text { Adjusted rate } \\
\text { ratio }(95 \% \mathrm{Cl})^{b, c}\end{array}$ & 1.0 (reference) & $0.75(0.53-1.06)$ & .106 \\
\hline $\begin{array}{l}\text { Adjusted hazard } \\
\text { ratio }(95 \% \mathrm{Cl})^{b, d}\end{array}$ & 1.0 (reference) & $0.78(0.55-1.11)$ & .169 \\
\hline
\end{tabular}

\footnotetext{
atatin use after diagnosis.

${ }^{b}$ Adjusted for sex, age, comorbidity, year of incidence, histologic grade, stage, microsatellite status, and chemotherapy.

${ }^{c}$ Poisson model.

${ }^{d}$ Cox model.
} 